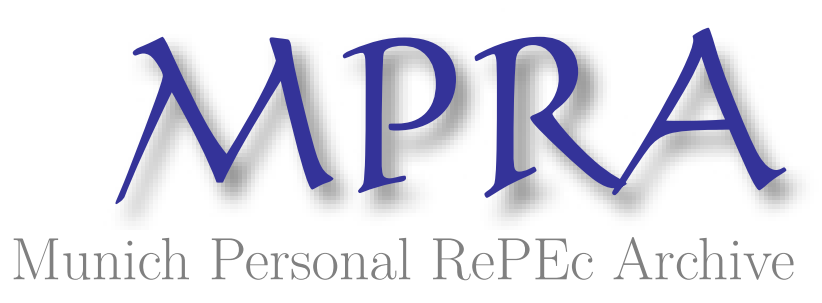

\title{
Why Has China not Embraced a Global Cap-and-Trade Regime?
}

Zhang, ZhongXiang

East-West Center

September 2003

Online at https://mpra.ub.uni-muenchen.de/12783/

MPRA Paper No. 12783, posted 16 Jan 2009 06:52 UTC 
September 2003

Slightly Revised (in red): July 2007

\title{
Why Has China not Embraced a Global Cap-and-Trade Regime?
}

\author{
ZhongXiang Zhang (张中祥), Ph.D in Economics \\ Senior Fellow \\ Research Program \\ East-West Center \\ 1601 East-West Road \\ Honolulu, HI 96848-1601 \\ United States \\ Tel: $+1-808-9447265$ \\ Fax: +1-808-944 7298 \\ Email: ZhangZ@EastWestCenter.org
}




\begin{abstract}
Many economic studies suggest that China would reap significant benefits from participating in a global cap-and-trade regime. The question then is that even if such a regime is so beneficial to China, why China has consistently refused in international negotiations even to discuss its participation in it. In this paper, we look at this issue from the following perspectives: a) from the point of view of fairness, how do developing countries including China and India perceive emissions caps in the first place?; b) why have China and India been sceptical to international emissions trading?; c) how is an inflow of CDM investment in China perceived politically in comparison with the exports of emissions permits to the U.S.?; d) what are the implications of "lock in" to emissions cap, in particular no rules and principles for setting emissions targets for the commitment periods subsequent to Kyoto?; e) how to address the complex undertaking of setting emissions caps for developing countries, which must be linked to future, unobserved levels in comparison with the historically observed levels for industrialized countries?. To our knowledge, this is the first paper to analyse why China has not embraced an international greenhouse gas emissions trading scheme, thus pointing out efforts/directions towards getting the country into such a scheme. Thus, the paper is of significant policy relevance.
\end{abstract}

Keywords: Cap-and-trade regime, Clean development mechanism, International climate negotiations, Kyoto Protocol, China, India 
Being the world's most populous country, China is a large greenhouse gas emissions source that grows rapidly in line with its industrialisation and urbanization, and has a great deal of low-cost greenhouse gas abatement options. That explains why many economic studies by Zhang (2000 and 2004) and those examined by Stanford University's Energy Modeling Forum (Weyant, 1999) show that China would reap significant benefits from participating in a global cap-and-trade regime. Even if such a regime is so beneficial to China, why has China consistently refused in international negotiations even to discuss its participation in it? I gauge at least five reasons for China's stance.

First and most importantly, participating emissions trading requires countries to take on emissions caps. However, developing countries including China and India consider it unfair to impose on emissions caps on developing countries in the first place until Annex 1 countries give clear signs that they have taken the lead required in cutting their own greenhouse gas emissions. Developing countries regard their emissions as survival emissions and those from Annex 1 countries as luxury emissions. Many economic studies (Weyant, 1999; Zhang, 2000 and 2004) premise that China would take on emissions caps and then calculate what outcomes would be for China. This is a classical way to address an issue of "what is" in positive economics. But China may not consider it as an issue of "what is". Instead, China may consider it as an issue of "what ought to be" in normative economics. Moreover, more than half the Group of 77 (G77) are even more vulnerable to climate change than other peers in this Group and thus demand deeper cuts in emissions to prevent dangerous climate change. Given China's desire for the unity of the G77, 
maintaining a united G77 front would necessitate taking their interests into account.

Pushing for stringent commitments by Annex 1 countries is just to that end and appears a better negotiating tactic to pursue than demanding more generous targets for developing countries themselves, in particular given that the current emissions commitments by Annex 1 countries are far short of what developing countries called for at Kyoto and had been relaxed substantially by allowing significant sinks credits in Marrakech Accords. ${ }^{1}$

Table 1 Quantitative Implications of the Marrakech Accords

\begin{tabular}{crrrrrrrr}
\hline Region & \multicolumn{2}{c}{$\begin{array}{c}\text { Baseline } \\
\text { emissions } \\
(\mathrm{MtC})\end{array}$} & \multicolumn{2}{c}{$\begin{array}{c}\text { Nominal } \\
\text { reduction } \\
(\% \text { wrt } 1990)\end{array}$} & $\begin{array}{c}\text { Effective } \\
\text { reduction } \\
\text { (\% wrt 2010) }\end{array}$ & $\begin{array}{c}\text { Absolute } \\
\text { cutback } \\
\text { (MtC wrt 2010) }\end{array}$ \\
& 1990 & 2010 & \multicolumn{2}{c}{ w/o sinks } & w/t sinks & w/o sinks & w/t sinks & w/o sinks w/t sinks \\
\hline AUN & 88 & 130 & -6.8 & -9.4 & 27.6 & 25.9 & 36 & 34 \\
CAN & 126 & 165 & 6.0 & -5.2 & 28.2 & 19.7 & 47 & 32 \\
EUR & 930 & 1040 & 7.8 & 6.2 & 17.5 & 16.1 & 182 & 168 \\
JPN & 269 & 330 & 6.0 & 1.1 & 23.4 & 19.4 & 77 & 64 \\
EEC & 279 & 209 & 7.1 & 4.9 & -24.0 & -26.9 & -50 & -56 \\
FSU & 853 & 593 & 0 & -4.2 & -43.8 & -49.8 & -260 & -296 \\
\hline Total w/o US & 2545 & 2467 & 4.3 & 0.9 & 1.3 & -2.2 & 32 & -54 \\
\hline USA & 1345 & 1809 & 7.0 & 3.7 & 30.9 & 28.4 & 558 & 514 \\
\hline Total w/t US & 3890 & 4276 & 5.2 & 1.9 & 13.8 & 10.8 & 590 & 460 \\
\hline
\end{tabular}

${ }^{a}$ AUN - Australia and New Zealand; CAN - Canada; EUR - OECD Europe; JPN Japan; EEC - Central and Eastern European countries; FSU - Former Soviet Union.

${ }^{\mathrm{b}}$ Annex B total without the U.S. ratification.

${ }^{\mathrm{c}}$ Annex B total with the U.S. ratification.

Source: Löschel and Zhang (2002).

${ }^{1}$ Significant sinks credits allowed in the Marrakech Accords relax the emissions targets substantially. Table 1 contains the nominal percentage reductions with respect to (wrt) 1990 emissions levels and the effective percentage reductions with respect to baseline emissions in 2010 for both the original Kyoto emissions targets and the revised targets under the Bonn Agreement and the Marrakech Accords. As a result of allowing countries to count the amount of sinks credits, the average reduction target for the Annex B countries as a whole is reduced to 1.9 percent, in comparison with the original reduction target of 5.2 percent (Löschel and Zhang, 2002). 
Second, China and India have been sceptical to international emissions trading. ${ }^{2}$ First, they are not convinced that international emissions trading would lead to actual reductions in emissions; instead, it would merely shift reductions overseas and is seen as a way for industrialized countries to avoid undertaking costly abatement actions at home. ${ }^{3}$ Clearly, this issue is related to target setting, not to emissions trading per se (Zhang, 1998). However, international emissions trading makes the issue explicit, thus raising these countries' suspicion against emissions trading. Second, China and India regard the present rather arbitrary allocation of assigned amounts to industrialised countries based on historical emission levels under the Kyoto Protocol as attempts to create new property rights for the atmosphere. At the international climate negotiations, they made it clear that any trading under Article 17 of the Kyoto Protocol does not bestow rights or entitlements to Annex B countries (UNFCCC, 1999). China and India insist that before emissions trading commences, the entitlements of both developed and developing countries have to be defined (Sharma, 1998). Third, China may consider that benefits of clean development mechanism (CDM) projects are real and at the same time, may perceive the positive outcomes that have been demonstrated in domestic emissions trading elusive. In principle, greenhouse gases offer an even more attractive case for application of emissions trading than many local pollutants already well handled with emissions trading. However, at the international level, emissions trading is being tested.

\footnotetext{
${ }^{2}$ The operation of the European Union (EU) Emissions Trading Scheme may help China and India to change their views on international emissions trading.

${ }^{3}$ In his statement to the COP3, Chen Yaobang, head of the Chinese delegation, rejected emissions trading and joint implementation schemes, insisting that these schemes were unacceptable because they would allow industrialised countries to shirk their responsibilities of cutting emissions at home while disregarding the living's environment of people in other countries (People's Daily, 1997).
} 
The successful U.S. $\mathrm{SO}_{2}$ Allowance Trading Program cannot just be transplanted into the international terrain where legal and institutional ingredients differ substantially from those in the U.S., not to mention no institutional and infrastructure supports for operating emissions trading in place in the majority of developing countries. ${ }^{4}$ This leaves it doubtful that China would perceive that emissions trading would work in practice to its advantage.

Third, China may perceive an inflow of CDM investment in China to be much less politically sensitive than the exports of emissions permits to the U.S.. In practice, CDM investment is most likely to be a climate component added to existing and future FDI (foreign direct investment) projects. Even in the optimistic case where the U.S. was engaged in the Kyoto Protocol, the total inflow of CDM investment in China in 2010 would be estimated to be a value of US\$ 1.7 billion even in the optimistic case of full global emissions trading (Zhang, 2000). This is only few percentage of the current total FDI in China, which is now about US\$ 60 billion. FDI has been serving as a powerful engine driving China's economic growth, and is perceived positively both inside and outside China. Binding with FDI would make an inflow of CDM investment in China

\footnotetext{
${ }^{4}$ Even for the U.S. $\mathrm{SO}_{2}$ Allowance Trading Program, the entire process from the U.S. Environmental Protection Agency beginning to compile the data for its allocation database in 1989 to publishing its final allowance allocations in March 2003 took almost four years (Harvey et al., 2003). For the first phase of the EU Emissions Trading Scheme, the entire process took almost two years from the EU publishing the Directive establishing a scheme for greenhouse gas emission allowance trading on July 23, 2003 to its approving the last national allocation plan for Greece on June 20, 2005 (Zhang, 2006). For a country like China with very weak environmental institutions and that does not have dependable data on emissions, fuel uses and outputs for installations, this allocation process is expected to take much longer than what experienced in the U.S. and the EU. This factor alone may lead China to give a second thought on the establishing of greenhouse gas emissions trading.
} 
become less explicit from those who regard CDM as "foreign aid". 5 By contrast, the U.S. has already had huge trade deficit with China, and exporting a large volume of surplus permits from China to the U.S. would further deteriorate the U.S. trade balance sheet with China. ${ }^{6}$ Such trade impacts are not expected to be big, but may well be taken out of the context and be used to tackle China for other real matters. ${ }^{7}$ Thus, China needs to treat, with caution, any issue that may potentially worsen the trade deficit that it has with the U.S.

Fourth, China is concerned about the implications of "lock in" to an emissions cap, in particular no rules and principles for setting emissions targets for the commitment periods subsequent to Kyoto. With the EU bubble treating its poorer member countries more leniently ${ }^{8}$ and the Russia Federation widely perceived to have been granted generous

${ }^{5}$ Rep. Bill Archer (R-Texas), Chair of the House Ways and Means Committee, for example, said that "It is another form of foreign aid" (Congressional Quarterly, 29 November 1997).

${ }^{6}$ McKibbin and Wilcoxen (2002) suggest that massive exports of permits would lead to appreciation of the exporting country's exchange rate and a decline in its exports other than permits. If China's exports of permits to the U.S. would counteract a decline in China's exports of goods and services to the U.S., then the U.S. trade balance sheet with China would not be deteriorated.

${ }^{7}$ When an issue in question has heavy dose of politics, no matter how small the impact the issue itself has, it can be amplified and taken out of the context making its potential implications non-trivial. Look at current Chinese food safety issue in the U.S.. No one would deny that China needs to take food safety concern seriously for the sake of both its own citizens and consumers elsewhere. However, the issue has been taken well beyond that context by the politicians and the media in the current situation of trade imbalance between the two countries.

${ }^{8}$ The 15 member countries of the EU are each listed with an $8 \%$ reduction from 1990 levels in Annex B to the Kyoto Protocol. In June 1998, the EU Council reached an agreement under which the commitments are redistributed among its member countries under the bubble provision as specified in Article 4 of the Protocol. This will now serve as the basis of EU ratification and the redefined targets will become the "quantified emission limitation and reduction commitments" for each EU member country under the 
targets at Kyoto, it is conceivable that industrialized countries will use the same tactics to bribe developing countries, giving them more generous emissions targets to enlist them to assume emissions commitments. No doubt, granting generous targets would be much less unattractive to developing countries than asking more stringent targets. Developing countries can even gain in the short term, provided that their targets are set even above their business-as-usual levels. But once developing countries assume emissions commitments, they are expected to take even more stringent targets over time, which are generally reviewed by developing countries themselves as impeding their economic development prospects. What matters is the balance between this short-term benefits and the perceived long-term costs to developing countries in terms of restrictions to future economic growth. In this regard, rules and principles for setting emissions targets for the commitment periods subsequent to Kyoto would help developing countries to make informed decision on whether to take on commitments. Such principles measure wide differences in national circumstances and at the same time, allow the necessary flexibility to accommodate great uncertainty throughout the policy-economics-biophysical system. These principles need to be agreed on via international negotiations. Such principles do not necessarily ensure that developing countries would take on commitments. However, if no such principles are made clear at the outset, the likelihood would be even less for developing

Protocol. Comparing the differentiated targets with the EU common $8 \%$ reduction commitments, we can see that the redistribution of the commitments has allocated more assigned amounts to the poor countries, whose emissions are expected to rise fast, than their allowed levels under the Protocol. By permitting a 25-27\% increase in emissions to Greece and Portugal, the EU internal burden sharing of its Kyoto commitments among the member countries clearly indicates that poorer countries should be treated more leniently. If Greece and Portugal can have this sort of rise, it would be very difficult for the EU to reject the demand from the really poor, that is, developing countries, for a not unreasonable leeway in emissions. 
countries to assume commitments in the first place, even if such commitments are hardly challenging to them.

Fifth, although many economic studies show that China would reap significant benefits from participating a global cap-and-trade regime, they don't really address the complex undertaking of setting emissions caps for developing countries. ${ }^{9}$ Emissions targets of Annex B countries are set against their historically observed levels. But for developing countries, their living standards are still very low in comparison with their industrialized counterparts, and they have legitimate demand for further development and economic growth. Thus, unlike Annex B countries, their targets, if any, must be linked to future, unobserved levels. Moreover, developing country economies tend to fluctuate more than those of industrialized countries. This will lead to considerable uncertainties over their economic growth rates and thus emissions projections. No doubt, the uncertainties would encourage developing countries to assume very pessimistic emissions targets when they are asked to take on commitments, thus raising great concern about the danger of generating "tropical hot air". This clearly suggests that it is not an easy matter to set emissions caps for developing countries to the satisfaction to themselves as well as to industrialized countries. ${ }^{10}$

\footnotetext{
${ }^{9}$ This point is somewhat related to the first point in the paper, but they discuss different issues. The first point focuses on why China should take on greenhouse gas emissions caps - prerequisite for international emissions trading, whereas the point touches on technical difficulty in setting emissions caps for countries like China. Because the first issue is more fundamental and this one is of technical nature, so the paper lists the first issue as the first reason and thus first discusses it. We could put them together, but I view points 2-4 in the paper are more important than this point. That is the reason why I discuss it as the last, fifth point.

${ }^{10}$ In the recent debate on "China about to become top carbon emitter" (Financial Times, 2007a) and "China rebuts carbon emission forecast" (Financial Times, 2007b), divergent
} 


\section{Acknowledgments}

This paper was originally written as part of the invited lead speech at the International

Conference on Reconstructing Climate Policy: Moving Beyond the Kyoto Impasse, 11-

12 May 2003, Duke University, and was subsequently presented at the International

Conference on Climate Policy after Marrakech: Towards Global Participation, 4-6

September 2003, Honolulu, USA. It has benefited from useful discussions with Jonathan

Wiener at Duke University and Richard Morgenstern at the Resources for the Future.

That said, the views expressed here are those of the author. The author bears sole responsibility for any errors and omissions that may remain.

\section{References}

Financial Times (2007a), China about to Become Top Carbon Emitter, April 19, Available at: $\quad$ http://www.ft.com/cms/s/d5289ae4-ee25-11db-8584000b5df10621,dwp_uuid=f6e7043e-6d68-11da-a4df-0000779e2340.html.

claims are provided regarding China overtaking the U.S. as the world's largest carbon emitter this year or next. The Chief Economist at International Energy Agency (IEA) said that that is going to happen, whereas the Chinese senior official at the National Coordination Committee on Climate Change rebutted that claim is lack of a statistical evidence. That IEA claim is an estimate for a future, based on current trends, although such an estimate is as short as for this year or next. It is not the historical records of carbon emissions. So using a lack of statistical basis to reject that claim is not compelling. But, disagreement between China and the IEA on China's carbon emissions just for one or two years ahead clearly illustrates how difficult to agree on emission levels in a rapidly developing country in the years not far from the future, not to mention to set emissions caps in the next decade or even longer time horizon. 
Financial Times (2007b), China Rebuts Carbon Emission Forecast, April 26, Available at: http://www.ft.com/cms/s/3b8459ca-f3eb-11db-88aa000b5df10621,dwp_uuid=9c33700c-4c86-11da-89df-0000779e2340.html.

Harvey, R., Kruger, J., Irving, W. (2003), U.S. Experience with $\mathrm{SO}_{2}$ and NOx Allowance Allocations, Clean Air Markets Division, U.S. Environmental Protection Agency, Washington, DC.

Löschel, A. and Z.X. Zhang (2002), The Economic and Environmental Implications of the US Repudiation of the Kyoto Protocol and the Subsequent Deals in Bonn and Marrakech, Weltwirtschaftliches Archiv - Review of World Economics, Vol. 138, No. 4, pp. 711-746.

McKibbin, W. J. and P.J. Wilcoxen (2002), Climate Change Policy After Kyoto: A Blueprint for a Realistic Approach, Washington: The Brookings Institution.

People's Daily (1997), Head of the Chinese Delegation Expounds China's Stance on Global Climate Change, Overseas Edition, December 9.

Sharma, A. (1998), Climate No Headway. Down to Earth 7, Centre for Science and Environment, New Delhi.

Stewart, R.B. and J.B. Wiener (2003), Reconstructing Climate Policy: Beyond Kyoto, American Enterprise Press, Washington, DC.

UNFCCC (1999), Mechanisms Pursuant to Articles 6, 12 and 17 of the Kyoto Protocol: Synthesis of Proposals by Parties on Principles, Modalities, Rules and Guidelines - Note by the Chairman, United Nations Framework Convention on Climate Change (UNFCCC), FCCC/SB/1999/INF.2/Add.2, Bonn. 
Weyant, J.P. (ed., 1999). The Cost of the Kyoto Protocol: A Multi-model Evaluation. Energy Journal, Vol. 20 (Special Issue on the Cost of the Kyoto Protocol), pp. 1398.

Zhang, Z.X. (1998), Greenhouse Gas Emissions Trading and the World Trading System, Journal of World Trade, Vol. 32, No. 5, pp. 219-239.

Zhang, Z.X. (2000), Estimating the Size of the Potential Market for the Kyoto Flexibility Mechanisms, Weltwirtschaftliches Archiv - Review of World Economics, Vol. 136, No. 3, pp. 491-521.

Zhang, Z.X. (2004), Meeting the Kyoto Targets: The Importance of Developing Country Participation, Journal of Policy Modeling, Vol. 26, No. 1, pp. 3-19.

Zhang, Z.X. (2006), Cutting Carbon Emissions While Making Money: A Wishful Thinking or A Win-Win Opportunity?, The Keynote Address at the Plenary Session on Making Money from Saving Carbon at the $29^{\text {th }}$ International Association for Energy Economics International Conference, Potsdam, Germany, June 8 . 